\title{
Effects of a selective educational system on fatigue, sleep problems, daytime sleepiness, and depression among senior high school adolescents in Taiwan
}

\author{
This article was published in the following Dove Press journal: \\ Neuropsychiatric Disease and Treatment \\ 19 March 2015 \\ Number of times this article has been viewed
}

\author{
Tien-Yu Chen ${ }^{1,2}$ \\ Yu-Ching Chou ${ }^{3}$ \\ Nian-Sheng Tzeng 1,2,4 \\ Hsin-An Chang ${ }^{1,2,4}$ \\ Shin-Chang Kuo 1,2,5 \\ Pei-Yin Pan ${ }^{1,2}$ \\ Yi-Wei Yeh ${ }^{1,2,5}$ \\ Chin-Bin Yeh ${ }^{1,2}$ \\ Wei-Chung Mao ${ }^{1,2,6}$ \\ 'Department of Psychiatry, Tri-Service \\ General Hospital, ${ }^{2}$ School of \\ Medicine, National Defense Medical \\ Center, ${ }^{3}$ School of Public Health, \\ National Defense Medical Center, \\ ${ }^{4}$ Student Counseling Center, National \\ Defense Medical Center, ${ }^{5} \mathrm{Graduate}$ \\ Institute of Medical Sciences, \\ National Defense Medical Center, \\ ${ }^{6}$ Institute of Brain Science, National \\ Yang-Ming University, Taipei, Taiwan, \\ Republic of China
}

Objective: The aim of the study reported here was to clarify the effects of academic pressure on fatigue, sleep problems, daytime sleepiness, and depression among senior high school adolescents in Taiwan.

Methods: This cross-sectional study enrolled 757 senior high school adolescents who were classified into four groups: Grade $1(n=261)$, Grade 2 ( $n=228)$, Grade 3T $(n=199$; Grade 3 students who had another college entrance test to take), and Grade 3S ( $=69$; Grade 3 students who had succeeded in their college application). Fatigue, sleep quality, daytime sleepiness, and depression were assessed using the Chinese version of the Multidimensional Fatigue Symptom Inventory - Short Form, Pittsburgh Sleep Quality Index-Taiwan Form, the Chinese version of the Epworth Sleepiness Scale, and the Chinese version of the Beck Depression Inventory ${ }^{\circledR}$-II (BDI-II), respectively.

Results: Physical, emotional, and mental fatigue scores were all higher in higher-grade groups. The Grade $3 \mathrm{~T}$ (test) students had the worst fatigue severity, and the Grade $3 \mathrm{~S}$ (success) students had the least fatigue severity. More than half of the students $(60.9 \%)$ went to bed after $12 \mathrm{am}$, and they had on average 6.0 hours of sleep per night. More than $30 \%$ of the students in Grade 2 (37.3\%) and Grades 3T/S (30.2\%/30.4\%) possibly had daily sleepiness problems. The students

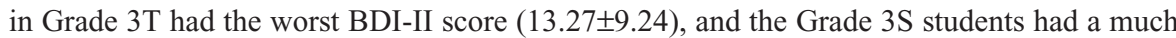
lower BDI-II score (7.91 \pm 6.13$)$.

Conclusion: Relatively high proportions of fatigue, sleep problems, daytime sleepiness, and depression among senior high school adolescents were found in our study. The severities of fatigue, sleep problems, and depression were significantly diminished in the group under less academic stress (Grade 3S). Our findings may increase the understanding of the mental health of senior high school students under academic pressure in Taiwan. Further large sample size and population-based study should be done for better understanding about this topic.

Keywords: academic stress, students, mental health, hours of sleep, school performance

\section{Introduction}

Fatigue is a subjective feeling and its ill effects are frequently seen in many ways, such as task performance decrement, ${ }^{1}$ cognitive impairment, and emotional disturbance. ${ }^{2}$ In school children, fatigue can lead to a decline in school performance, negative health outcomes, and refusal to attend school. ${ }^{3}$ A study in the UK reported that $11 \%$ of participants aged 11 to 14 years and $17 \%$ of participants aged 13 to 16 years showed severe fatigue. ${ }^{4}$ In another study in the Netherlands, $20.5 \%$ of female participants and
Correspondence: Wei-Chung Mao Department of Psychiatry, Tri-Service General Hospital, Number 325, Section 2, Cheng-Gung Rd, Neihu District, Taipei,

I I4, Taiwan, Republic of China

Tel +886 287927220

Fax +886287927221

Email maosleep@gmail.com 
$6.5 \%$ of male participants reported severe fatigue. ${ }^{5}$ Therefore, the influence of fatigue on children and adolescents is an important issue worthy of further research.

Fatigue and daytime sleepiness in adolescents are associated with sleep problems, psychosocial impacts, and medical disorders. ${ }^{6}$ Several studies have reported that adolescents require a similar duration of sleep to younger children, up to -9.00-9.25 hours per night. However, the reported average duration of sleep in adolescents is around 7.00-7.5 hours, with only $20 \%$ sleeping up to 9 hours..$^{7-9}$ Adolescents not only sleep for a shorter time than they require, ${ }^{10}$ but they also go to bed and wake up later than younger children. ${ }^{11}$ The lack of adequate sleep and excessive daytime sleepiness in adolescent students may increase the risks of cognitive and emotional disturbances, poor academic performance, and injury. ${ }^{12}$ Possible explanations for the sleep pattern of adolescents are the effects of adolescent physical development, ${ }^{13}$ school tasks and pressure, ${ }^{14}$ circadian rhythm change, ${ }^{15}$ emotional disturbance, ${ }^{16}$ part-time jobs, and extracurricular activities. ${ }^{17}$

Academic pressure and school schedule have been shown to be the major sources of depression and anxiety for Asian adolescents. ${ }^{18,19}$ For example, one Korean study found that academic stress could be one of the predictors of suicidal behavior among Korean adolescents. ${ }^{20}$ Several cross-cultural studies also found that Asian students experience higher academic stress compared with their Western peers. ${ }^{21-23}$ In Taiwan, students attend senior high school for 3 years (Grades 1-3) at the ages of 16 to 18 years. Each academic year starts in September and ends the following June. There is a 1-month winter vacation in January or February (depending on the lunar calendar), and a 2-month summer vacation over July and August. Senior high school students used to take the Joint College Entrance Exam in July, and the pressure to pass this test was very high. ${ }^{24,25}$ Parents and teachers place an enormous amount of academic pressure on adolescents in Taiwan, and more than $80 \%$ of senior high school students attend a cram school for further academic study after school hours, and many senior high schools also provide extra lessons during long vacations. ${ }^{24}$ In 2002, the Ministry of Education in Taiwan adopted a selective educational system called the "General Scholastic Ability Test" (GSAT) with the aim of reducing academic stress. This system was established to give as many high school students as possible the chance to matriculate before graduation. The GSAT is held in January for Grade 3 students. For students who wish to obtain college admission, a higher GSAT score is required, and then they need to take the Recommendation-Selection Admission Program, which is held by distinct departments of each college. This Recommendation-Selection Admission Program requests applicants provide details of special achievements attained during their high school years, and the admission test is an oral exam or interview. Application results are released in April. For those who fail in the GSAT or Recommendation-Selection Admission Program, another exam, the Advanced Subjects Test (AST) is held in July, replacing the Joint College Entrance Exam. Students need to pass the AST to earn a second chance to enter college. ${ }^{26}$ Although the purpose of the new educational policy was to guide to standardize teaching and reduce academic pressure, some studies found that it cost students and parents more money for the extra studying in cram schools and the academic pressure was still high. ${ }^{26,27}$ Ambitious parents long to see their children succeed academically, they pressure school teachers, and therefore out-of-school tuition is still a thriving business for Chinese students. ${ }^{28}$ Such high academic pressure is also seen in South Korea and Singapore. ${ }^{29-31}$

To the best of our knowledge, no study has systematically evaluated the relationship between academic pressure and the different dimensional aspects of fatigue in Chinese senior high school adolescents. The aim of the study reported here, therefore, was to clarify the interaction between fatigue and academic stress, and sleep problems and mental health in senior high school adolescents in Taiwan. Previous studies have revealed that academic pressure is one of the most influential factors in Asian high school students' daily life, ${ }^{18,23,27,30}$ but were unsure about the level of the impact, so we did our assessment at a particular time, in April. At this time, some of the Grade 3 students had succeeded in their college applications, while others were still struggling with their preparations for the coming exam. Our hypothesis was that the stress from the request for academic achievement would play a role in these students' fatigue, sleep, mood, and daytime sleepiness. We did within-group (in Grade 3) and among-group (in Grades 1-3) comparisons in order to gain a view of the whole picture of the interaction between academic pressure and students' mental and physical condition. Moreover, fatigue was surveyed by a multidimensional scale for a comprehensive understanding of fatigue. We tried to figure out its correlates and possible predictors to better understand fatigue in adolescents.

\section{Methods \\ Participants and procedures}

This study was performed in a medium-sized senior high school in Taipei. Students (757 in total, 228 female) from all three high school grades (Grades 1-3) were recruited 
(effective response rate: $97.2 \%$ ). Data from cross-sectional surveys were collected in April 2005, when some of the Grade 3 students had already attended the GSAT in January and succeeded in their college application.

School counselors helped our research group to conduct the surveys. The inclusion criteria were: (1) no current general medical condition, (2) agreement to complete all questionnaires, and (3) approval of the usage of their personal information and evaluation results. Individual characteristics included age, school grade, sex, height, weight, and smoking habit. Self-administered questionnaires included the Chinese version of the Multidimensional Fatigue Symptom Inventory-Short Form (MFSI-SF-C), the Pittsburgh Sleep Quality Index-Taiwan Form (PSQI-T), the Chinese version of the Epworth Sleepiness Scale (CESS), and the Chinese version of the Beck Depression Inventory ${ }^{\circledR}$-II (C-BDI-II). The protocol of this research conformed to the Declaration of Helsinki.

\section{Instruments}

\section{Chinese version of the Multidimensional Fatigue Symptom Inventory-Short Form}

Fatigue is thought to be a multidimensional construct. ${ }^{32-34}$ Stein et al developed the Multidimensional Fatigue Symptom Inventory with five domains - general fatigue, emotional fatigue, mental fatigue, physiological fatigue, and vigor. ${ }^{34}$ It has been validated in several populations including patients with cancer or chronic fatigue syndrome, and healthy subjects with prominent fatigue symptoms. ${ }^{34-36}$ The Multidimensional Fatigue Symptom Inventory measures fatigue in these five domains with 83 questions. The 30 -item short-form questionnaire, the Multidimensional Fatigue Symptom InventoryShort Form (MFSI-SF) was established in 2004 by Stein et al. ${ }^{33}$ Each item is rated on a five-point scale indicating how true the statement was during the last week $(0=$ not at all, $4=$ extremely). The scores are summed for the first four subscales (general, physical, emotional, and mental fatigue) and the vigor scale is subtracted to obtain a total fatigue score. ${ }^{33}$

The Chinese version (MFSI-SF-C) was translated by Pien et al with four subscales, and it has been reported to be both reliable and valid. ${ }^{37}$ The Cronbach's alpha for the MFSISF-C total scale and subscales ranged from 0.83 to $0.92 .{ }^{37}$ The physical fatigue subscale in the Chinese version is an assortment of general and physical fatigue items from the original form. The emotional fatigue subscale of the Chinese version adds item 11 ("I am confused") and deleted items 3 ("I feel angry") and 8 ("I feel nervous") from the original inventory. This tool can be used to assess participants' physical, emotional, and mental fatigue, and vigor domains over the previous 7 days. ${ }^{37}$

\section{Pittsburgh Sleep Quality Index-Taiwan Form}

The Pittsburgh Sleep Quality Index (PSQI) is a 19-item selfreported questionnaire that evaluates sleep quality during the previous month. ${ }^{38}$ The PSQI-T was translated by Wang et $\mathrm{al}^{39}$ and it has been shown to be both valid and reliable..$^{39,40}$ The Cronbach's alpha for the PSQI-T was $0.79 .{ }^{40}$ Each item of the PSQI is scored from 0 to 3 , with a score of 0 indicating no difficulty and a score of 3 indicating severe difficulty. The 19 items are grouped into seven component scores: subjective sleep quality, sleep latency, sleep duration, habitual sleep efficiency, sleep disturbances, use of sleep medication, and daytime dysfunction. The total PSQI score ranges from 0 to 21 . A cut-off score of 5 is used to distinguish poor from good sleepers. ${ }^{38}$

\section{Chinese version of the Epworth Sleepiness Scale}

The Epworth Sleepiness Scale, a self-rated questionnaire, was designed to measure daytime sleepiness in eight different situations. ${ }^{41}$ Each answer is scored on a scale of 0 to 3 . The total score in the range of 10-24 is thought to indicate that the subject requires medical advice. Validation of the Chinese version was done by Chen et al and the Cronbach's alpha was $0.81 .^{42}$ In the current study, only items $1-7$ were included, as the last item, "falling asleep at the wheel", was not relevant to the students.

\section{Chinese version of Beck Depression Inventory-II}

The BDI-II is a 21-item self-rated inventory that evaluates levels of depression by evaluating depressive symptoms, cognitive function, and physical symptoms during the previous 2 weeks. ${ }^{43}$ The Chinese version of the BDI-II (C-BDI-II) has been shown to have good internal consistency and test-retest reliability. ${ }^{44}$ The Cronbach's alpha for the C-BDI-II was $0.94 .{ }^{44}$ Participants are asked to evaluate how they have been feeling for the past 2 weeks. Each item is scored from 0 to 3, and a total score from 14-19 indicates mild depression, 20-28 shows moderate depression, and 29-63 exhibits severe depression.

\section{Statistical analysis}

All statistical analyses were performed using SPSS software (v 22; IBM Corporation, New York, USA), and a $P$-value $<0.05$ was considered to be statistically significant. Descriptive results of categorical variables are described as frequency $(\%)$, and continuous variables are described as mean \pm standard deviation (SD). Group differences were 
evaluated by Pearson's chi-square test and one-way analysis of variance with the Bonferroni post hoc test. Analysis of variance was also conducted to compare differences in mental and emotional fatigue item scores in each grade. The correlation analyses of fatigue severity and total scores of PSQI-T, CESS, and C-BDI-II were done by Spearman's correlation. A linear regression model was used to identify the variables that were associated with the three MFSI-SF-C fatigue domains.

\section{Results}

\section{Demographics of the participants}

Table 1 outlines the characteristic information of the participants. We collected 757 valid questionnaires and classified the gathered data into four groups according to grade and whether they had already succeeded in the GSAT (S) or still had the AST test (T) to take in July: Grade $1(n=261 ; 34.5 \%)$, Grade $2(n=228 ; 30.2 \%)$, Grade $3 \mathrm{~T}(\mathrm{n}=199 ; 26.3 \%)$, and Grade $3 \mathrm{~S}(\mathrm{n}=69 ; 9 \%)$. The age of the enrolled students ranged from 16 to 18 years, with an average 1-year difference among each grade. There were no statistical differences in sex, body mass index (BMI), or smoking history.

\section{Fatigue, sleep problems, daytime sleepiness, and depressive severity}

The cross-sectional surveys were performed in April, when the Grade 3S students had already succeeded in the GSAT and their college application. Significant differences were found between different groups in the self-rated questionnaires (Table 2). Fatigue inventory scores for physical, emotional, and mental fatigue increased as grade increased. The Grade 3T students had the worst fatigue scores and the Grade 3S students had obviously better scores (all fatigue domains had $P$-values $<0.05)$.

The mean (SD) scores of the PSQI-T were above the cut-off score of 5 in all four groups, and the scores were higher in the higher grades. More than half of the students went to bed after $12 \mathrm{am}$, and the average sleep duration was less than 7 hours in each group. The students in Grade 3T had the worst sleep quality, with a total score of 6.39 (2.85) and shortest total sleeping hours at 5.81 (0.97).

The mean scores of the CESS representing daytime sleepiness showed that none of the four groups went beyond the cut-off point of 9 . Nevertheless, a significant difference was still seen between the four groups $(P=0.018)$, and more than $30 \%$ of students in Grade 2 $(37.3 \%)$ and Grade $3 \mathrm{~T} / \mathrm{S}(30.2 \% / 30.4 \%)$ possibly had daily sleepiness problems.

The mean (SD) self-reported C-BDI-II scores were higher in the higher grades. The highest average score was found in Grade 3T (13.27 [9.24]), and the lowest in Grade 3S (7.91 [6.13]), which was much lower than in the other three groups, and the $P$-value among the four groups was $<0.001$.

\section{Subscales of the Chinese version of the MFSI-SF-C}

Table 3 presents the scores of the mental and emotional fatigue subscales associated with the participants' learning condition and mental health. The scores on items 1, 20, and 25 on the mental fatigue subscale were significantly different among the four groups. The Grade 3T students, who were preparing for the AST, had the highest scores in item 20

Table I Comparison of demographic factors by group ${ }^{\mathrm{a}}$

\begin{tabular}{|c|c|c|c|c|c|}
\hline Demographic & Grade I & Grade 2 & Grade 3T & Grade 3S & $P$ \\
\hline \multicolumn{6}{|l|}{ Sex } \\
\hline Male & 177 (67.8) & I64 (7I.9) & $139(69.8)$ & $49(7 I)$ & 0.795 \\
\hline Female & 84 (32.2) & $64(28.1)$ & $60(30.2)$ & $20(29)$ & \\
\hline Total, N & $261(100.0)$ & $228(100.0)$ & $199(100.0)$ & $69(100.0)$ & \\
\hline Age, years & $15.97 \pm 0.53$ & $16.83 \pm 0.49$ & $|7.62 \pm 0.5|$ & $17.61 \pm 0.52$ & $<0.001 *$ \\
\hline BMI, kg/m² & $21.37 \pm 2.99$ & $21.26 \pm 3.28$ & $21.58 \pm 3.23$ & $21.25 \pm 3.16$ & 0.748 \\
\hline$<25$ & 234 (87.9) & 200 (87.7) & I73 (86.9) & $62(89.9)$ & 0.787 \\
\hline$\geq 25$ & $27(10.3)$ & $28(12.3)$ & $26(13.1)$ & $7(10.1)$ & \\
\hline \multicolumn{6}{|l|}{ Smoking history } \\
\hline Yes & $\mathrm{I}(0.4)$ & $5(2.2)$ & $3(1.5)$ & $0(0)$ & 0.221 \\
\hline No & $260(99.6)$ & $223(97.8)$ & $196(98.5)$ & $69(100.0)$ & \\
\hline
\end{tabular}

Notes: aData are presented as $\mathrm{n}(\%)$ or mean \pm standard deviation. $* \mathrm{p}<0.001$.

Abbreviations: $3 \mathrm{~T}$, still had a test to take; $3 \mathrm{~S}$, success in college application; BMI, body mass index. 
Table 2 Comparison of the MFSI-SF-C, PSQI-T, CESS, and C-BDI-II scores by group

\begin{tabular}{|c|c|c|c|c|c|c|}
\hline Scale & Grade I ${ }^{a}$ & Grade $2^{a}$ & Grade $3 T^{a}$ & Grade $3 S^{a}$ & $\boldsymbol{P}$ & Bonferroni post hoc ${ }^{b}$ \\
\hline Total MFSI-SF-C & $|3.67 \pm| 6.6 \mid$ & $13.93 \pm 17.44$ & $17.43 \pm 17.75$ & $7.68 \pm 12.82$ & $0.001 *$ & $2,3 \mathrm{~T}>3 \mathrm{~S}$ \\
\hline Physical fatigue & $11.93 \pm 8.56$ & $|2.3| \pm 8.59$ & $13.27 \pm 9.23$ & $9.47 \pm 6.28$ & $0.017^{*}$ & $3 \mathrm{~T}>3 \mathrm{~S}$ \\
\hline Emotional fatigue & $5.00 \pm 4.13$ & $5.46 \pm 4.44$ & $6.48 \pm 4.29$ & $4.00 \pm 3.65$ & $<0.00 I^{* *}$ & $3 \mathrm{~T}>\mathrm{I}, 3 \mathrm{~S}$ \\
\hline Mental fatigue & $5.79 \pm 3.96$ & $6.40 \pm 4.02$ & $6.4 I \pm 4.19$ & $4.56 \pm 3.56$ & $0.003^{*}$ & $2,3 \mathrm{~T}>3 \mathrm{~S}$ \\
\hline Vigor & $9.05 \pm 4.80$ & $10.23 \pm 4.50$ & $8.80 \pm 4.69$ & $|0.35 \pm 4.3|$ & $0.002 *$ & $2>1,3 T$ \\
\hline Total PSQI-T & $5.73 \pm 2.48$ & $6.18 \pm 2.64$ & $6.39 \pm 2.85$ & $5.30 \pm 2.12$ & $0.004 *$ & $3 \mathrm{~T}>\mathrm{I}, 3 \mathrm{~S}$ \\
\hline \multicolumn{7}{|l|}{ Time to bed } \\
\hline Before midnight & $129(49.4)$ & $72(31.6)$ & $68(34.2)$ & $27(39.1)$ & $<0.00 I^{* *}$ & \\
\hline After midnight & $132(50.6)$ & $156(68.4)$ & $|3|(65.8)$ & $42(60.9)$ & & \\
\hline Total sleep hours & $6.19 \pm 0.98$ & $5.92 \pm 0.92$ & $5.8 I \pm 0.97$ & $6.10 \pm 0.85$ & $<0.00 I^{* *}$ & $\mathrm{I}>2,3 \mathrm{~T}$ \\
\hline CESS (items I-7) & $7.90 \pm 3.15$ & $8.66 \pm 3.69$ & $8.13 \pm 3.17$ & $7.40 \pm 3.22$ & $0.018^{*}$ & $2>3 S$ \\
\hline$\leq 9$ & $197(75.5)$ & 143 (62.7) & $139(69.8)$ & $48(69.6)$ & $0.025^{*}$ & \\
\hline$>9$ & $64(24.5)$ & $85(37.3)$ & $60(30.2)$ & $21(30.4)$ & & \\
\hline Total C-BDI-II & $10.23 \pm 8.27$ & $12.10 \pm 10.42$ & $13.27 \pm 9.24$ & $7.91 \pm 6.13$ & $<0.00 I^{* *}$ & $3 \mathrm{~T}>\mathrm{I}, 3 \mathrm{~S} ; 2>3 \mathrm{~S}$ \\
\hline Mild (14-19) & $38(14.6)$ & $33(14.5)$ & $41(20.6)$ & $9(13.0)$ & $0.002 *$ & \\
\hline Moderate (20-28) & $27(10.3)$ & $29(12.7)$ & $34(17.1)$ & $4(5.8)$ & & \\
\hline Severe (29-63) & $9(3.4)$ & $19(8.3)$ & $12(6.0)$ & $0(0)$ & & \\
\hline
\end{tabular}

Notes: a Data are presented as $n(\%)$ or mean \pm standard deviation. ${ }^{b}$ I, Grade I; 2, Grade 2; 3T, Grade 3T; 3S, Grade 3S. $* P<0.05$; **P $<0.00 \mathrm{I}$.

Abbreviations: $3 \mathrm{~T}$, still had a test to take; 3S, success in college application; MFSI-SF-C, Chinese version of the Multidimensional Fatigue Symptom Inventory-Short Form; PSQI-T, Pittsburgh Sleep Quality Index-Taiwan Form; CESS, Chinese version of the Epworth Sleepiness Scale; C-BDI-II, the Chinese version of the Beck Depression Inventory ${ }^{\circledR}-I I$.

("I am unable to concentrate" $[F=5.30, P<0.001])$ and 25 ("I make more mistakes than usual" $[F=4.58, P=0.003])$. They also had the worst scores in every emotional fatigue item ("I felt confused" $[F=6.05, P<0.001]$, “. . sad" $[F=3.68$, $P=0.012]$, “ $\ldots$ depressed” $[F=5.00, P=0.002]$, “. $\ldots$ tense $[F=5.69, P=0.001]$, and “ $\ldots$ distressed" $[F=7.27, P<0.001])$, with similar results in the C-BDI-II scale.

\section{Correlation analysis between the MFSI-SF-C, PSQI-T, CESS, and C-BDI-II}

We used Spearman's correlation analysis to evaluate the correlation toward fatigue and other mental conditions
(Table 4). The results of correlation coefficient $(\rho)$ among total MFSI-SF-C scores and total scores of PSQI-T, CESS, and C-BDI-II were $\rho=0.53(P<0.001), \rho=0.38(P<0.001)$, and $\rho=0.68(P<0.001)$, respectively.

\section{Regression model of MFSI-SF-C domains}

The MFSI-SF-C evaluates physical, emotional, and mental fatigue domains to capture the full spectrum of fatigue. The results of the generalized linear model revealed that the participants' depressive level, sleep quality, and daytime sleepiness were significantly related to the physical fatigue domain and accounted for $37.1 \%$ of the variance (Table 5).

Table 3 Mental and emotional fatigue item scores: comparison by group

\begin{tabular}{|c|c|c|c|c|c|c|c|}
\hline Item & Grade Ia & Grade $2^{\mathbf{a}}$ & Grade $3 T^{a}$ & Grade $3 \mathbf{S}^{\mathbf{a}}$ & $\boldsymbol{F}$ & $P$ & Bonferroni post hoc ${ }^{b}$ \\
\hline \multicolumn{8}{|l|}{ Mental fatigue } \\
\hline I. I have trouble remembering things & $1.12 \pm 0.92$ & $1.32 \pm 0.96$ & $1.20 \pm 0.97$ & $0.97 \pm 0.88$ & 3.07 & $0.027^{*}$ & $2>3 S$ \\
\hline I5. I have trouble paying attention & $1.29 \pm 1.07$ & $1.46 \pm 1.04$ & $1.45 \pm 1.07$ & $1.15 \pm 1.00$ & 2.53 & 0.056 & \\
\hline 20. I am unable to concentrate & $1.10 \pm 1.01$ & $1.26 \pm 1.01$ & $1.32 \pm 1.07$ & $0.81 \pm 0.90$ & 5.30 & $0.001 *$ & $2,3 \mathrm{~T}>3 \mathrm{~S}$ \\
\hline 25. I make more mistakes than usual & $0.90 \pm 1.00$ & $0.92 \pm 0.95$ & $1.04 \pm 1.04$ & $0.53 \pm 0.84$ & 4.58 & $0.003^{*}$ & $\mathrm{I}, 2,3 \mathrm{~T}>3 \mathrm{~S}$ \\
\hline 27. I am forgetful & $1.38 \pm 1.18$ & $1.44 \pm 1.14$ & $1.39 \pm 1.17$ & $1.10 \pm 1.05$ & 1.49 & 0.216 & \\
\hline \multicolumn{8}{|l|}{ Emotional fatigue } \\
\hline II. I am confused & $1.30 \pm 1.07$ & $1.39 \pm \mathrm{I} .14$ & $1.62 \pm 1.13$ & $1.01 \pm 1.03$ & 6.05 & $<0.00 I^{* *}$ & $3 \mathrm{~T}>\mathrm{I}, 3 \mathrm{~S}$ \\
\hline 13. I feel sad & $0.91 \pm 1.03$ & $1.07 \pm 1.10$ & $1.09 \pm 0.99$ & $0.68 \pm 0.85$ & 3.68 & $0.012^{*}$ & $2,3 \mathrm{~T}>3 \mathrm{~S}$ \\
\hline 2I. I feel depressed & $0.88 \pm 1.00$ & $0.97 \pm 1.10$ & $1.16 \pm 1.07$ & $0.65 \pm 0.88$ & 5.00 & $0.002 *$ & $3 \mathrm{~T}>\mathrm{I}, 3 \mathrm{~S}$ \\
\hline 23. I feel tense & $0.96 \pm 0.99$ & $0.95 \pm 0.96$ & $1.29 \pm 1.07$ & $0.93 \pm 0.92$ & 5.69 & $0.00 I^{*}$ & $3 \mathrm{~T}>\mathrm{I}, 2$ \\
\hline 30. I am distressed & $0.94 \pm 1.02$ & $1.07 \pm 1.09$ & $1.32 \pm 1.10$ & $0.74 \pm 0.91$ & 7.27 & $<0.00 I^{* *}$ & $3 \mathrm{~T}>\mathrm{I}, 3 \mathrm{~S}$ \\
\hline
\end{tabular}

Notes: ${ }^{2}$ Data are presented as mean \pm standard deviation. ${ }^{b}$ I, Grade I; 2 , Grade 2; 3T, Grade 3T; 3S, Grade 3S. $* P<0.05 ; * * P<0.001$.

Abbreviations: $3 \mathrm{~T}$, still had a test to take; $3 \mathrm{~S}$, success in college application. 
Table 4 Spearman's correlation coefficients (rho: $\rho$ ) between the MFSI-SF-C, PSQI-T, CESS, and C-BDI-II

\begin{tabular}{lllll}
\hline Scale & MFSI-SF-C & PSQI-T & CESS & C-BDI-II \\
\hline MFSI-SF-C & 1.00 & - & - & - \\
PSQI-T & 0.53 & 1.00 & - & - \\
CESS & 0.38 & 0.27 & 1.00 & - \\
C-BDI-II & 0.68 & 0.49 & 0.31 & 1.00 \\
\hline
\end{tabular}

Note: All correlations are significant at $P<0.001$.

Abbreviations: MFSI-SF-C, Chinese version of the Multidimensional Fatigue Symptom Inventory-Short Form; PSQI-T, Pittsburgh Sleep Quality Index-Taiwan Form; CESS, Chinese version of the Epworth Sleepiness Scale; C-BDI-II, the Chinese version of the Beck Depression Inventory ${ }^{\circledR}$-II

Sex, BMI, depressive level, and sleep quality were significantly associated with the emotional fatigue domain, accounting for $41.9 \%$ of the variance. Grade difference, sex, depressive level, sleep quality, and daytime sleepiness were significantly associated with the mental fatigue domain, accounting for $36.6 \%$ of the variance.

Among the independent variables, depression and sleep quality clearly played the most consequential roles in each fatigue domain. Daytime sleepiness was significantly associated with physical and mental fatigue, and there were differences by sex in both emotional and mental fatigue domains.

In summary, the fatigue domains of the senior high school students were mostly associated with depressive symptoms, sleep quality, daytime sleepiness, and sex.

\section{Discussion}

This study demonstrates a relatively high proportion of fatigue, sleep disturbance, daytime sleepiness, and depression in senior high school adolescents of each grade in Taiwan.
We also investigated how the educational system and college entrance examination influenced fatigue and sleep in these students, which has rarely been discussed in Western countries. Our findings show that the severity of fatigue, sleep problems, and depressive symptoms were worse in the students in higher grades, which is consistent with previous studies in various countries. ${ }^{16,45,46}$ Nevertheless, the students in Grade 3S, those who had already succeeded with their college application, were less fatigued, had better sleep, and reported better moods compared with their Grade 3T peers. This implies that academic pressure rather than age is the most important factor with regard to adolescent health in Taiwan, similar to a previous study in junior high school students in Taipei. ${ }^{14}$

Fatigue was the major focus of our study due to its high prevalence in contemporary adolescents. Previous studies have reported that $6.5 \%$ to $30.6 \%$ of adolescents experience severe fatigue, with the differences being attributable to study design and the enrolled subjects. ${ }^{4,5,47}$ There is no reported cut-off value in the MFSI-SF to define fatigue, and the original study by Stein et a ${ }^{34}$ reported that the mean total MFSI-SF score was 0.85 in healthy adults. The mean (SD) score of fatigue was 13.67 (16.61) in the Grade 1 students and 17.43 (17.75) in the Grade 3T students compared with 7.68 (12.82) in the Grade 3S students who were under much less academic pressure (Table 2). This result confirms the relationship between academic stress and fatigue in senior high school adolescents in Taiwan.

Table 3 shows the value of the multidimensional fatigue scale. A previous study reported that fatigue and sleepiness are associated with cognitive deficits in areas such as

Table 5 Regression analysis of each fatigue domain of the MFSI-SF-C with related variables $(n=757)$

\begin{tabular}{|c|c|c|c|c|c|c|c|c|c|}
\hline \multirow[t]{2}{*}{ Variable } & \multicolumn{3}{|c|}{ Physical fatigue } & \multicolumn{3}{|c|}{ Emotional fatigue } & \multicolumn{3}{|c|}{ Mental fatigue } \\
\hline & B & SE & $P$ & B & SE & $P$ & B & SE & $P$ \\
\hline \multicolumn{10}{|l|}{ Grade } \\
\hline 2 & -0.868 & 0.762 & 0.256 & -0.136 & 0.364 & 0.708 & -0.449 & 0.358 & 0.209 \\
\hline $3 T$ & -0.022 & 1.043 & 0.983 & 0.686 & 0.498 & 0.168 & -0.910 & 0.490 & 0.064 \\
\hline $3 S$ & -1.013 & 1.237 & 0.413 & -0.235 & 0.590 & 0.691 & -1.452 & 0.581 & $0.013^{*}$ \\
\hline Age, years & -0.296 & 0.490 & 0.546 & -0.084 & 0.233 & 0.719 & 0.410 & 0.230 & 0.075 \\
\hline Sex: female/male ${ }^{a}$ & 0.628 & 0.556 & 0.259 & 0.690 & 0.265 & $0.009 *$ & 0.826 & 0.261 & $0.002 *$ \\
\hline BMI: $<25 / \geq 25 \mathrm{~kg} / \mathrm{m}^{2, b}$ & -1.449 & 0.801 & $0.07 I$ & -0.856 & 0.380 & $0.025^{*}$ & -0.264 & 0.374 & 0.481 \\
\hline C-BDI-II & 0.446 & 0.031 & $<0.001 * *$ & 0.271 & 0.015 & $<0.00 I^{* *}$ & 0.226 & 0.014 & $<0.00 I^{* *}$ \\
\hline PSQI-T: $\leq 5 />5^{c}$ & 2.521 & 0.553 & $<0.00 I^{* *}$ & 0.853 & 0.263 & $0.001 *$ & 0.595 & 0.259 & $0.022^{*}$ \\
\hline CESS: $\leq 9 />9^{d}$ & 2.937 & 0.569 & $<0.001 * *$ & 0.353 & $0.27 I$ & 0.193 & 1.325 & 0.267 & $<0.00 I^{* *}$ \\
\hline Adjusted $R^{2}$ & $0.37 I$ & & $<0.00 I^{* *}$ & 0.419 & & $<0.001 * *$ & 0.366 & & $<0.001 * *$ \\
\hline
\end{tabular}

Notes: ${ }^{a}$ Sex: $0=$ female, $I=$ male; ${ }^{b} B M I: 0=<25 \mathrm{~kg} / \mathrm{m}^{2}, \mathrm{I}=\geq 25$; $\mathrm{cPSQI}-\mathrm{T}: 0=\leq 5, \mathrm{I}=>5$; ${ }^{\mathrm{d}} \mathrm{CESS}: 0=\leq 9 ; \mathrm{I}=>9$. ${ }^{*} \mathrm{P}<0.05 ; * * P<0.00 \mathrm{I}$.

Abbreviations: $3 \mathrm{~T}$, still had a test to take; 3S, success in college application; B, unstandardized coefficients; SE, standard error; CESS, Chinese version of Epworth Sleepiness Scale; C-BDI-II, the Chinese version of the Beck Depression Inventory ${ }^{\circledR}$-II; BMI, body mass index; PSQI-T, Pittsburgh Sleep Quality Index-Taiwan Form; MFSI-SF-C, Chinese version of the Multidimensional Fatigue Symptom Inventory-Short Form. 
academic performance, processing, and motor speed. ${ }^{48} \mathrm{We}$ used five questions to screen mental fatigue and found that the students under the greatest academic pressure (Grade 3T) had the worst score in item 20 ("I am unable to concentrate") and 25 ("I make more mistakes than usual"), and a borderline significant difference in item 1 ("I have trouble remembering things") and 15 ("I have trouble paying attention"). The students in Grade 3T should be expected to perform the best cognitively of all the students to prepare for the highly competitive college entrance exam; however, they seemed to have the worst cognitive condition. Sleep laboratory studies have shown that abnormal sleep patterns in children are correlated with impairments in intellectual functions. ${ }^{49,50}$ Extended sleep is essential for the recovery of central nervous system injuries to improve cognitive performance, quality of life, fatigue severity, and general well-being. ${ }^{51}$ Therefore, students in Taiwan should be educated on how to achieve adequate nocturnal sleep, especially when they are preparing for examinations.

Fatigue in adolescents has been reported to be related to sleep problems, psychiatric disorders, organic illnesses, female sex, physical inactivity, and medications..$^{46,47}$ The correlation analysis of our data demonstrates a high correlation coefficient between fatigue, sleep problems, depression, and daytime sleepiness (Table 4). Our findings also show that depressive symptoms increased the risk of physical, emotional, and mental fatigue (Table 5). There may be substantial clinical overlap between fatigue and depression; however, it has been reported that fatigue and depression have different neuroendocrine responses..$^{52}$ In addition, one epidemiological study also showed independent heritability of fatigue and depression. ${ }^{53}$ Two previous studies reported that psychological distress manifesting as depression was prospectively expressed to predict fatigue in adolescents. ${ }^{17,54}$ The severity of sleepiness was also able to predict fatigue in the current study, consistent with findings from studies in Japan and Finland..$^{45,55}$ The male participants in our study had a higher risk of emotional and mental fatigue than their female peers, which is in contrast to previous findings. ${ }^{4,54}$ One possible explanation for this is a sample-size effect, as twice as many male students as female students were enrolled. Another possible explanation may be related to Chinese culture. In Taiwan, some parents are still male-oriented, and, from childhood, boys are expected to perform better academically than girls. ${ }^{45}$

Depression is one of the most prevalent psychiatric disorders among adolescents, ${ }^{56}$ and it is associated with impairments in family, academic, social functioning, ${ }^{57}$ and sleep disorders. ${ }^{58}$ Depression has also been associated with important public-health issues such as suicide attempts and substance-use behavior in adolescents. ${ }^{59}$ In the current study, up to $43.7 \%$ of the Grade $3 \mathrm{~T}$ students had mild to severe depression (Table 2), compared with only $18.8 \%$ of their Grade 3S peers. This indicates that many of the students had reversible depressive symptoms and that academic stress was one of the major risk factors. Similar results were also seen in the analysis of emotional fatigue items (Table 3 ) and total fatigue scores (Table 2). We also found a high correlation rate among depression, fatigue, and sleep problems (Table 4). These results suggest that mood, fatigue severity, and sleep problems in students under high academic pressure should have more attention paid to them.

Sleep problems in adolescents is another interesting topic. Recent studies have reported that sleep problems in school-aged children are more prevalent in the Chinese population than in Western countries. ${ }^{60,61}$ One study reported that Chinese senior high school students have an hour less of sleep per night than their American counterparts. ${ }^{62}$ The average duration of sleep of our participants was around 6.0 hours per night. This result was substantially lower than that in other studies in Europe and America (approximately 8 hours). ${ }^{16,63}$ Previous studies in Taiwan have reported a longer average duration of sleep than our study -7.36 (junior high school) and 6.7 (university) hours. ${ }^{14,64} \mathrm{We}$ also found that the Grade 1 senior high school students had the longest mean (SD) duration of sleep of 6.19 (0.98) hours, compared with 5.81 (0.97) hours in Grade 3T students. In addition, more than $50 \%$ of our participants went to bed after midnight in each grade, and this reached $68.4 \%$ and $65.8 \%$ in Grade 2 and Grade 3T, respectively. A high prevalence rate of cram school attendance (up to $80 \%$ ) in the evening ${ }^{24}$ and keen academic competition may explain the late bed time. Because all senior high school students in Taiwan have to be at school by 8 am or earlier, they need to get up at 6 am or $7 \mathrm{am}$. Attending cram school, staying up late, and then rising early to go to school can lead to an insufficient amount of sleep. In addition, the mean total PSQI-T scores were above the cut-off point of 5 in each group, and a significant difference was noted between Grade 3T and 3S. These results indicate that academic stress can be one of the factors that influences sleep quality. However, even those experiencing less academic stress (Grade 3S) still showed some difficulties in sleeping (mean PSQI-T score: 5.30 \pm 2.12 ; total sleep time: $6.10 \pm 0.85$ hours). One explanation for the poor sleep quality in these Grade $3 \mathrm{~S}$ students could be spending a lot of time on the Internet; it is possible that students under less academic 
pressure spend more time doing recreational activities including surfing the Internet. Internet addiction is a current major public-health problem around the world, especially in adolescents. ${ }^{65}$ Many adolescents put much effort into playing online games and attending to their social media accounts. Several Asian studies have reported that inappropriate Internet use is associated with shorter sleep duration, depressive symptoms, and obesity in adolescents. ${ }^{66,67}$

In addition, specific sleep disorders should be considered in adolescents. They can be classified as primary (insomnia, delayed sleep-phase syndrome) or secondary (eg, sleep-disordered breathing). The polysomnographic study is considered a standard examination to evaluate specific sleep disorders. ${ }^{6}$ Sleep-disordered breathing was estimated to affect $1 \%-3 \%$ of adolescents. ${ }^{6}$ It can be related to airway abnormalities ${ }^{69}$ and obesity. ${ }^{70}$ Sleep-disordered breathing may affect adolescents' executive function, ${ }^{71}$ and waist circumference is considered as a reliable index in predicting the risk of it. ${ }^{70}$ The obesity $\left(\mathrm{BMI}>25 \mathrm{~kg} / \mathrm{m}^{2}\right.$ ) rate of our participants was $11.6 \%$. Although there was no significant difference between obesity and total PSQI-T scores in our subjects, we should be aware of its effects. Moreover, several studies reported that nocturnal enuresis might affect at least $1 \%-2 \%$ adolescents $^{72}$ and this is considered to be related to abnormal sleep structure ${ }^{73}$ and learning disability. ${ }^{74}$ Further studies are needed to clarify the impact of these findings on adolescent sleep problems in Taiwan.

Daytime sleepiness (CESS score $>9$ ) was noted in more than $30 \%$ of the students in Grades 2 and 3 in our study, which is a similar finding to that of a study in Canada. ${ }^{75}$ Sleepiness is thought to be associated with multiple factors, including sleep problems, societal demands, depression, attention deficit disorder, ${ }^{75}$ and medical conditions. ${ }^{76}$ In our study, sleepiness was also possibly a risk factor for physical and mental fatigue. There was no significant difference in CESS score between Grade 3T and 3S students. Furthermore, more than $30 \%$ of the subjects in Grade $3 \mathrm{~S}$ had severe daytime sleepiness. This implies that there are reasons in addition to academic stress causing daytime sleepiness. Getting up early to school could be one possible explanation. Our subjects had to attend school by 7.30 am in the morning. Rushing to avoid traffic, having an insufficient breakfast, and insufficient sleep could be risk factors of daytime sleepiness. Several studies have determined that delayed high school start times have significant benefits for adolescents, such as less daytime sleepiness, improved attendance, and decreased levels of fatigue and depression. ${ }^{77,78}$

\section{Limitations}

Although our findings help to extend the understanding of fatigue, sleep, and related problems in Taiwanese adolescents, there were some limitations to this study. First, the self-reported questionnaires may have been affected by cognitive bias and subjects' cooperation, particularly in adolescents. However, we visited each class and thoroughly explained the questionnaires to the participants. The teachers also encouraged the students to answer the questionnaires carefully. Most of the results also met our expectations.

Second, this was a cross-sectional study performed over a short period of 1 year, which makes it difficult to establish causality. Further longitudinal studies are necessary to confirm our findings.

Third, the academic stress was not estimated by an authorized scale such as the Academic Expectations Stress Inventory. ${ }^{79}$ Nevertheless, many studies have shown that Asian students are under relatively more academic stress than students in Western countries. ${ }^{21-23}$ Previous studies have also shown the significant relationship between academic stress and mood (either depression or anxiety) in Asian adolescents. ${ }^{18-20}$ This is both evidence-based and empirical knowledge for our study design.

Finally, there were fewer female subjects $(30 \%)$ in this study, and this may have influenced the results with regard to sex. Nevertheless, our study had a high effective response rate of $97.2 \%$, and almost all of the students in the school were included in the study.

Further studies should take these factors into consideration.

\section{Conclusion}

The most important finding of this study is to show the negative effects of a selective education system with regard to academic stress on senior high school adolescents in Taiwan. We found a relatively high proportion of fatigue, sleep problems, daytime sleepiness, and depression among the senior high school students, and demonstrated the association between fatigue and other factors. Senior students under the highest level of academic stress had the worst mental and emotional fatigue scores, which were possibly related to cognitive performance and depression. Dramatic differences of less fatigue and better mental status were found in the students under less academic stress. In spite of the limitations, we still believe that our findings are useful to understand the similarities and differences in fatigue and mental status among adolescents in other Asian countries. 
Our findings suggest that those who deal with students of this age should consider academic pressure as an important factor in Chinese adolescents' health.

\section{Acknowledgments}

We sincerely thank Dr Chang-Chih Huang, Dr Chih-Sung Liang, Dr Pei-Shen Ho, and Dr San-Yuan Huang for their assistance in data management.

\section{Disclosure}

The authors report no conflicts of interest in this work.

\section{References}

1. Chalder T, Berelowitz G, Pawlikowska T, et al. Development of a fatigue scale. J Psychosom Res. 1993;37(2):147-153.

2. Lewis G, Wessely $\mathrm{S}$. The epidemiology of fatigue: more questions than answers. J Epidemiol Community Health. 1992;46(2):92-97.

3. Fukuda S, Yamano E, Joudoi T, et al. Effort-reward imbalance for learning is associated with fatigue in school children. Behav Med. 2010; 36(2):53-62.

4. Viner RM, Clark C, Taylor SJ, et al. Longitudinal risk factors for persistent fatigue in adolescents. Arch Pediatr Adolesc Med. 2008;162(5): 469-475.

5. ter Wolbeek M, van Doornen LJ, Kavelaars A, Heijnen CJ. Severe fatigue in adolescents: a common phenomenon? Pediatrics. 2006;117(6): e1078-e1086.

6. Fisher M. Fatigue in adolescents. J Pediatr Adolesc Gynecol. 2013;26(5): 252-256.

7. Mercer PW, Merritt SL, Cowell JM. Differences in reported sleep need among adolescents. J Adolesc Health. 1998;23(5):259-263.

8. Tarokh L, Raffray T, Van Reen E, Carskadon MA. Physiology of normal sleep in adolescents. Adolesc Med State Art Rev. 2010;21(3): 401-417.

9. Owens JA. Etiologies and evaluation of sleep disturbances in adolescence. Adolesc Med State Art Rev. 2010;21(3):430-445.

10. Carskadon MA. Patterns of sleep and sleepiness in adolescents. Pediatrician. 1990;17(1):5-12.

11. Carskadon MA, Vieira C, Acebo C. Association between puberty and delayed phase preference. Sleep. 1993;16(3):258-262.

12. Dahl RE, Lewin DS. Pathways to adolescent health sleep regulation and behavior. J Adolesc Health. 2002;31(6 Suppl):175-184.

13. Carskadon MA, Harvey K, Duke P, Anders TF, Litt IF, Dement WC. Pubertal changes in daytime sleepiness. 1980. Sleep. 1980;2(4): 453-460.

14. Gau SF, Soong WT. Sleep problems of junior high school students in Taipei. Sleep. 1995;18(8):667-673.

15. Wyatt JK. Circadian rhythm sleep disorders. Pediat Clin N Amer. 2011; 58(3):621-635.

16. Sarchiapone M, Mandelli L, Carli V, et al. Hours of sleep in adolescents and its association with anxiety, emotional concerns, and suicidal ideation. Sleep Med. 2014;15(2):248-254.

17. Laberge L, Ledoux E, Auclair J, et al. Risk factors for work-related fatigue in students with school-year employment. J Adolesc Health. 2011; 48(3):289-294.

18. Tan JB, Yates S. Academic expectations as sources of stress in Asian students. Soc Psychol Educ. 2011;14(3):389-407.

19. Sastry J, Ross CE. Asian ethnicity and the sense of personal control. Soc Psychol Q. 1998;61:101-120.

20. Juon HS, Nam JJ, Ensminger ME. Epidemiology of suicidal behavior among Korean adolescents. J Child Psychol Psychiatry. 1994;35(4): 663-676.
21. Chen C, Stevenson HW. Motivation and mathematics achievement: a comparative study of Asian-American, Caucasian-American, and east Asian high school students. Child Dev. 1995;66(4):1214-1234.

22. Ang RP, Huan VS, Braman OR. Factorial structure and invariance of the academic expectations stress inventory across Hispanic and Chinese adolescent samples. Child Psychiatry Hum Dev. 2007;38(1):73-87.

23. Ang RP, Klassen RM, Chong WH, et al. Cross-cultural invariance of the Academic Expectations Stress Inventory: adolescent samples from Canada and Singapore. J Adolesc. 2009;32(5):1225-1237.

24. Lin DD, Chen YF. [Cram school attendance and college entrance exam scores of senior high school students in Taiwan.] Bulletin of Educational Research. 2006;52(4):35-70. Chinese.

25. Shyu HY, Huang LL. [The relation of academic self-efficacy to academic outcomes for senior high school students.] Journal of Education and Psychology. 1999;22(2):267-294. Chinese.

26. Chin MC. Better or worse: examining the feasibility of the college multiple entrance program. Educational Policy Forum. 2004;7(2):59-84. Chinese.

27. Chin MC, Wen TH. Better or worse: examining the outcomes of the 20-year educational reforms in Taiwan. Journal of Education Research. 2014;245:5-21. Chinese.

28. Shek DT, Chan LK. Hong Kong Chinese parents' perceptions of the ideal child. J Psychol. 1999;133(3):291-302.

29. Mordkowitz ER, Ginsburg HP. Early academic socialization of successful Asian American college students. Quarterly Newsletter of the Laboratory of Comparative Human Cognition. 1987;9:85-91.

30. Lee M, Larson R. The Korean "examination hell": long hours of studying, distress, and depression. J Youth Adolesc. 2000;29(2):249-272.

31. Isralowitz RE, Hong OT. Singapore youth: the impact of social status on perceptions of adolescent problems. Adolescence. 1990;25(98): 357-362.

32. Richardson A. Measuring fatigue in patients with cancer. Support Care Cancer. 1998;6(2):94-100.

33. Stein KD, Jacobsen PB, Blanchard CM, Thors C. Further validation of the multidimensional fatigue symptom inventory-short form. $J$ Pain Symptom Manage. 2004;27(1):14-23.

34. Stein KD, Martin SC, Hann DM, Jacobsen PB. A multidimensional measure of fatigue for use with cancer patients. Cancer Pract. 1998;6(3): $143-152$.

35. Smith MS, Buchwald DS, Bogart A, Goldberg J, Smith WR, Afari N. Adolescent offspring of mothers with chronic fatigue syndrome. J Adolesc Health. 2010;46(3):284-291.

36. Lim W, Hong S, Nelesen R, Dimsdale JE. The association of obesity, cytokine levels, and depressive symptoms with diverse measures of fatigue in healthy subjects. Arch Intern Med. 2005;165(8):910-915.

37. Pien LC, Chu H, Chen WC, et al. Reliability and validity of a Chinese version of the Multidimensional Fatigue Symptom Inventory-Short Form (MFSI-SF-C). J Clin Nurs. 2011;20(15-16):2224-2232.

38. Buysse DJ, Reynolds CF 3rd, Monk TH, Berman SR, Kupfer DJ. The Pittsburgh Sleep Quality Index: a new instrument for psychiatric practice and research. Psychiatry Res. 1989;28(2):193-213.

39. Wang RC, Wang SJ, Chang YC, Lin CC. Mood state and quality of sleep in cancer pain patients: a comparison to chronic daily headache. J Pain Symptom Manage. 2007;33(1):32-39.

40. Tzeng JI, Fu YW, Lin CC. Validity and reliability of the Taiwanese version of the Pittsburgh Sleep Quality Index in cancer patients. Int J Nurs Stud. 2012;49(1):102-108.

41. Johns MW. A new method for measuring daytime sleepiness: the Epworth sleepiness scale. Sleep. 1991;14(6):540-545.

42. Chen NH, Johns MW, Li HY, et al. Validation of a Chinese version of the Epworth sleepiness scale. Qual Life Res. 2002;11(8):817-821.

43. Beck AT, Steer RA, Brown GK. Manual for the Beck Depression Inventory-II. San Antonio, TX: Psychological Corporation; 1996

44. Lu ML, Che HH, Chang SW, Shen WW. Reliability and validity of the Chinese version of the Beck Depression Inventory-II. Taiwanese Journal of Psychiatry. 2002;16(4):301-310. 
45. Zou N, Kubota M, Kuruma E, Kojima C, Nagai A. Fatigue status in relation to lifestyle in healthy Japanese adolescents. Int J Pediatr. 2010; 2010(2010):Article ID 520320.

46. Hazama GI, Inoue Y, Kojima K, Ueta T, Nakagome K. The prevalence of probable delayed-sleep-phase syndrome in students from junior high school to university in Tottori, Japan. Tohoku J Exp Med. 2008;216(1):95-98.

47. Ghandour RM, Overpeck MD, Huang ZJ, Kogan MD, Scheidt PC. Headache, stomachache, backache, and morning fatigue among adolescent girls in the United States: associations with behavioral, sociodemographic, and environmental factors. Arch Pediatr Adolesc Med. 2004;158(8):797-803.

48. Neu D, Kajosch H, Peigneux P, Verbanck P, Linkowski P, Le Bon O. Cognitive impairment in fatigue and sleepiness associated conditions. Psychiatry Res. 2011;189(1):128-134.

49. Esposito M, Carotenuto M. Borderline intellectual functioning and sleep: the role of cyclic alternating pattern. Neurosci Lett. 2010;485(2): 89-93.

50. Esposito M, Carotenuto M. Intellectual disabilities and power spectra analysis during sleep: a new perspective on borderline intellectual functioning. J Intellect Disabil Res. 2014;58(5):421-429.

51. Walker MP, van der Helm E. Overnight therapy? The role of sleep in emotional brain processing. Psychol Bull. 2009;135(5):731-748.

52. Cleare AJ, Bearn J, Allain T, et al. Contrasting neuroendocrine responses in depression and chronic fatigue syndrome. J Affect Disord. 1995; 34(4):283-289.

53. Williamson RJ, Purcell S, Sterne A, et al. The relationship of fatigue to mental and physical health in a community sample. Soc Psychiatry Psychiatr Epidemiol. 2005;40(2):126-132.

54. Rimes KA, Goodman R, Hotopf M, Wessely S, Meltzer H, Chalder T. Incidence, prognosis, and risk factors for fatigue and chronic fatigue syndrome in adolescents: a prospective community study. Pediatrics. 2007;119(3):e603-e609.

55. Tynjälä J, Kannas L, Levälahti E. Perceived tiredness among adolescents and its association with sleep habits and use of psychoactive substances. J Sleep Res. 1997;6(3):189-198.

56. Costello EJ, Mustillo S, Erkanli A, Keeler G, Angold A. Prevalence and development of psychiatric disorders in childhood and adolescence. Arch Gen Psychiatry. 2003;60(8):837-844.

57. Merry S, McDowell H, Hetrick S, Bir J, Muller N. Psychological and/or educational interventions for the prevention of depression in children and adolescents. Cochrane Database Syst Rev. 2004;(1):CD003380.

58. Carotenuto M, Esposito M, Parisi L, et al. Depressive symptoms and childhood sleep apnea syndrome. Neuropsychiatr Dis Treat. 2012;8: 369-373.

59. O’Neil KA, Conner BT, Kendall PC. Internalizing disorders and substance use disorders in youth: comorbidity, risk, temporal order, and implications for intervention. Clin Psychol Rev. 2011;31(1):104-112.

60. Li S, Jin X, Yan C, Wu S, Jiang F, Shen X. Bed- and room-sharing in Chinese school-aged children: prevalence and association with sleep behaviors. Sleep Med. 2008;9(5):555-563.

61. Li S, Zhu S, Jin X, et al. Risk factors associated with short sleep duration among Chinese school-aged children. Sleep Med. 2010;11(9): 907-916.
62. Liu X, Liu L, Owens JA, Kaplan DL. Sleep patterns and sleep problems among schoolchildren in the United States and China. Pediatrics. 2005;115(1 Suppl):241-249.

63. Knutson KL, Lauderdale DS. Sociodemographic and behavioral predictors of bed time and wake time among US adolescents aged 15 to 17 years. J Pediatr. 2009;154(3):426-430.

64. Kang JH, Chen SC. Effects of an irregular bedtime schedule on sleep quality, daytime sleepiness, and fatigue among university students in Taiwan. BMC Public Health. 2009;9:248.

65. Christakis DA. Internet addiction: a 21st century epidemic? BMC Med. 2010;8:61.

66. Do YK, Shin E, Bautista MA, Foo K. The associations between selfreported sleep duration and adolescent health outcomes: what is the role of time spent on Internet use? Sleep Med. 2013;14(2):195-200.

67. Tang J, Yu Y, Du Y, Ma Y, Zhang D, Wang J. Prevalence of internet addiction and its association with stressful life events and psychological symptoms among adolescent internet users. Addict Behav. 2014; 39(3):744-747.

68. Carotenuto M, Parisi P, Esposito M, Cortese S, Elia M. Sleep alterations in children with refractory epileptic encephalopathies: a polysomnographic study. Epilepsy Behav. 2014;35:50-53.

69. Santamaria F, Esposito M, Montella S, et al. Sleep disordered breathing and airway disease in primary ciliary dyskinesia. Respirology. 2014;19(4): 570-575.

70. Carotenuto M, Bruni O, Santoro N, Del Giudice EM, Perrone L, Pascotto A. Waist circumference predicts the occurrence of sleepdisordered breathing in obese children and adolescents: a questionnairebased study. Sleep Med. 2006;7(4):357-361.

71. Esposito M, Antinolfi L, Gallai B, et al. Executive dysfunction in children affected by obstructive sleep apnea syndrome: an observational study. Neuropsychiatr Dis Treat. 2013;9:1087-1094.

72. Nappo S, Del Gado R, Chiozza ML, Biraghi M, Ferrara P, Caione P. Nocturnal enuresis in the adolescent: a neglected problem. BJU international. 2002;90(9):912-917.

73. Esposito M, Gallai B, Parisi L, et al. Primary nocturnal enuresis as a risk factor for sleep disorders: an observational questionnaire-based multicenter study. Neuropsychiatr Dis Treat. 2013;9:437-443.

74. Esposito M, Carotenuto M, Roccella M. Primary nocturnal enuresis and learning disability. Minerva Pediatr. 2011;63(2):99-104.

75. Gibson ES, Powles AC, Thabane L, et al. "Sleepiness" is serious in adolescence: two surveys of 3,235 Canadian students. BMC Public Health. 2006;6:116.

76. Esposito M, Roccella M, Parisi L, Gallai B, Carotenuto M. Hypersomnia in children affected by migraine without aura: a questionnaire-based case-control study. Neuropsychiatr Dis Treat. 2013;9:289-294.

77. Wahlstrom K. Changing times: findings from the first longitudinal study of later high school start times. NASSP Bulletin. 2002;86:3-21.

78. Owens JA, Belon K, Moss P. Impact of delaying school start time on adolescent sleep, mood, and behavior. Arch Pediatr Adolesc Med. 2010;164(7):608-614.

79. Ang RP, Huan VS. Academic expectations stress inventory (AESI): Development, factor analysis, reliability and validity. Educ Psychol Meas. 2006;66:522-539.
Neuropsychiatric Disease and Treatment

\section{Publish your work in this journal}

Neuropsychiatric Disease and Treatment is an international, peerreviewed journal of clinical therapeutics and pharmacology focusing on concise rapid reporting of clinical or pre-clinical studies on a range of neuropsychiatric and neurological disorders. This journal is indexed on PubMed Central, the 'PsycINFO' database and CAS,
Dovepress

and is the official journal of The International Neuropsychiatric Association (INA). The manuscript management system is completely online and includes a very quick and fair peer-review system, which is all easy to use. Visit http://www.dovepress.com/testimonials.php to read real quotes from published authors. 